\title{
A NOTE ON THE HERMITE-HADAMARD INEQUALITY FOR CONVEX FUNCTIONS ON THE CO-ORDINATES
}

\author{
FEIXIANG CHEN
}

Abstract. In this paper, we obtain some new Hermite-Hadamard-type inequalities for convex functions on the co-ordinates. We conclude that the results obtained in this work are the refinements of the earlier results.

Mathematics subject classification (2010): 26D15, 52A40. ordinates.

Keywords and phrases: Hermite-Hadamard's inequality, convex function, convex functions on the co-

\section{REFERENCES}

[1] M. Alomari AND M. Darus, The Hadamard's inequality for $s$-convex functions of 2-variables on the co-ordinates, Int. J. Math. Anal., 2, 13 (2008), 629-638.

[2] M. Alomari And M. Darus, On The Hadamard's inequality for log-convex functions on the coordinates, J. Inequal. Appl., 2009, 2009: 283147.

[3] M. Bessenyei And Zsolt PÁles, Hadamard-type inequalities for generalized convex functions, Math. Inequal. Appl., 6, 3 (2003), 379-392.

[4] S. S. DRAGOMIR, On the Hadamard's inequality for convex functions on the co-ordinates in a rectangle from the plane, Taiwanese J. Math., 5, 4 (2001), 775-788.

[5] S. S. DRAGOMIR, Hermite-Hadamard's type inequalities for operator convex functions, Appl. Math. Comput., 218, 3 (2011), 766-772.

[6] S. S. DRAGOMIR, Hermite-Hadamard's type inequalities for convex functions of selfadjoint operators in Hilbert spaces, Linear Algebra Appl., 436, 5 (2012), 1503-1515.

[7] Abdallah El Farissi, Simple proof and refinement of Hermite-Hadamard inequality, J. Math. Inequal., 4, 3 (2010), 365-369.

[8] XIANG GAO, A note on the Hermite-Hadamard inequality, J. Math. Inequal., 4, 4 (2010), 587-591.

[9] M. A. LATIF AND M. Alomari, On Hadamard-type inequalities for $h$-convex functions on the coordinates, Int. J. Math. Anal. 3, 33 (2009), 1645-1656.

[10] M. A. LATIF AND S. S. DRAGOMIR, On some new inequalities for differentiable co-ordinated convex functions, J. Inequal. Appl., 2012, 2012:28.

[11] M. E. Özdemir, H. Kavurmaci, A. O. Akdemir And M. Avci, Inequalities for convex and $s$-convex functions on $\Delta=[a, b] \times[c, d]$, J. Inequal. Appl., 2012, 2012:20.

[12] M. E. ÖZDEMIR, ÇETIN YILDIZ AND A. O. AKDEMIR, On some new Hadamard-Type inequalities for co-ordinated quasi-convex functions, Hacet. J. Math. Stat. 41, 5 (2012), 697-707. 